\title{
O tocoginecologista, o patologista e o exame de Papanicolaou
}

\author{
The ObGyn, the pathologist and the pap smear test
}

O câncer do colo (CC) uterino, por se tratar de uma doença de distribuição mundial e de grande prevalência entre os países menos desenvolvidos, tem sido considerado como um dos indicadores de desenvolvimento da saúde de um povo. Isto porque, sendo o colo uterino um órgão de fácil acesso ao exame especular, considera-se inadmissível o diagnóstico tardio desta doença, sendo a proporção de casos invasores um parâmetro da qualidade do serviço de saúde da população ${ }^{1}$. Os dados sugerem que em todo o planeta ocorram cerca de 500 mil casos novos anuais de CC com 270 mil mortes ${ }^{1}$. Em nosso país, informações do Instituto Nacional do Câncer (Inca) indicam cerca de 19 mil casos novos para o ano de $2006^{2}$.

A detecção precoce tem se mostrado como importante fator redutor da morbidade e da mortalidade devido a essa doença ${ }^{3}$. Fundamentalmente, o exame utilizado como método de prevenção por meio da detecção precoce avalia as células coletadas do colo uterino e foi originalmente proposto por Papanicolaou e Traut ${ }^{4}$ e Papanicolaou ${ }^{5}$. Entretanto, a obtenção e manutenção de um programa de rastreamento sistemático com alta cobertura populacional, mesmo com aumento do intervalo entre as coletas, têm se mostrado fundamental para o controle da doença e vários países têm conseguido até mesmo a eliminação da moléstia por meio dessa organização ${ }^{6}$. Várias metodologias para coletas e muitas nomenclaturas foram empregadas para os laudos ${ }^{7,8}$. Embora ainda seja o método mais utilizado no mundo para o rastreamento do CC, a citologia apresenta percentuais de sensibilidade e especificidade diversos e, em alguns serviços, os índices relativamente baixos de sensibilidade comprometem a eficiência e a credibilidade desta metodologia de exame do rastreamento.

Este fato foi evidenciado nos Estados Unidos quando, a partir de 1980, devido às demandas jurídicas relacionadas a erros médicos, várias políticas foram propostas. Assim, os falsos-negativos da citologia foram mais bem estudados, principalmente porque pacientes com resultados negativos apresentaram-se com câncer invasor em curto intervalo de tempo após o exame ${ }^{9}$. Devido também a estas dificuldades, convocou-se uma reunião de especialistas na cidade de Bethesda, Estados Unidos, em 1988, e, entre as conclusões, foi ressaltada a importância de se descreverem as alterações visualizadas nas células contidas no esfregaço, bem como chamar atenção para a melhor adequação do preparado citológico $^{10,11}$. Igualmente no Brasil, em reunião de consenso com Sociedades

Correspondência:

Newton Sergio de Carvalho Rua Saldanha Marinho, 1.422, apto. 801 CEP 80430-160 - Curitiba/PR

E-mail: newton@hc.ufpr.br

Recebido

06/07/2007

Aceito com modificações 06/07/2007

\footnotetext{
Professor Adjunto do Departamento de Tocoginecologia do Hospital de Clínicas da Universidade Federal do Paraná - UFPR - Curitiba (PR), Brasil.

2Professor Adjunto do Departamento de Patologia do Hospital de Clínicas da Universidade Federal do Paraná - UFPR - Curitiba (PR), Brasil.
} 
de várias especialidades, foi definida a Nomenclatura Brasileira para Laudos Citopatológicos Cervicais, bem como recomendações de condutas para os laudos alterados ${ }^{12}$. É importante notar que a classificação de Bethesda, nas duas versões posteriores (1991 e 2001), para tentar aumentar os índices de sensibilidade, aumentou o enfoque e a valorização da avaliação das células glandulares além das escamosas, que já eram usuais. Além disto, criou uma nova denominação para aqueles casos em que as alterações não se apresentavam de uma forma definida, que foi chamada de "alterações celulares de significado indeterminado"8. Isto, tanto para células escamosas (ASC-US ou ASC-H) como para as glandulares (AGC), embora as condutas adotadas sejam diferentes conforme a sua origem.

Ainda, na perspectiva de melhorar a sensibilidade e se avaliarem os elementos que poderiam contribuir para esta melhora, vários estudos indicavam que a reavaliação das lâminas com posterior reclassificação era útil como controle de qualidade ${ }^{8,13}$. No Brasil, em estudo desenvolvido no estado do Paraná, foram revistas 65.753 lâminas. Houve uma taxa de discordância em $2,9 \%$ dos casos e se encontraram resultados que se modificaram frente à reavaliação, sobretudo para aqueles laudos negativos, que se elevaram de 83,5 para $84,5 \%$, e para as atipias indeterminadas, que aumentaram de 5,4 para $6,2 \%^{12}$. Outro ponto igualmente importante é a revisão dos casos negativos e, neste particular, avaliar a eficiência da revisão rápida de $100 \%$ dos casos para detecção dos casos falsos-negativos é o tema de publicação neste fascículo ${ }^{14}$. Neste estudo, dos 141 esfregaços suspeitos pela revisão rápida, $84(59,6 \%)$ foram confirmados pelo diagnóstico final, sendo que destes, $36(25,5 \%)$ foram classificados como células escamosas atípicas de significado indeterminado, que têm se mostrado como um dos principais diagnósticos ao qual o citopatologista e o clínico devem atentar.

Alguns pontos podem ser implicados para melhorar os índices de sensibilidade e, dentre eles, podemos destacar a coleta adequada.

Embora possa haver controvérsias a respeito da influência da amostra na qualidade da interpretação dos resultados, Sebastião et al. ${ }^{8}$, em estudo avaliando a adequabilidade da amostra e a presença do diagnóstico de ASCUS, demonstraram a importância deste item. Entre 1.507 casos de alterações em células escamosas de significado indeterminado, encontraram que 83,5\% eram satisfatórios para análise (1.258 casos). Entre aqueles satisfatórios, mas limitados, o fator principal foi a presença de sangue dificultando a visualização das células. Os resultados demonstraram que a presença de sangue na lâmina induz o citopatologista ao superdiagnóstico de ASCUS e que a presença de adequado esfregaço auxilia no fornecimento correto do laudo.

Em outro estudo, revisando laudos citológicos de duas unidades de saúde (US), Longatto Filho et al. ${ }^{15}$ analisaram 10.438 laudos e compararam os números de casos positivos em grupos de amostras com diferente qualidade: satisfatórias e satisfatórias, porém limitadas por ausência de células da junção escamo-colunar (JEC), dessecamento, fundo purulento ou por outras causas. Foram considerados positivos os casos com diagnóstico de atipias de significado indeterminado, NIC graus 1 a 3 e carcinoma. Confirmaram a necessidade de amostragem adequada e, em especial, a representatividade de células da JEC. A análise estatística mostrou que, nas duas unidades, a porcentagem de casos positivos foi significativamente maior no grupo de amostras obtidas consideradas satisfatórias (3,2 e 5,2\%, respectivamente na US1 e US2) do que nas limitadas por ausência de células da JEC, dessecamento e outras causas. Concluem que há necessidade de amostragem adequada especialmente com a representatividade de células da JEC.

Para se obter a representatividade adequada, em nosso meio é utilizada coleta em zona de transformação e no canal cervical com escova, distendendo-se o esfregaço em única lamina. Com esta metodologia de coleta, demonstrou-se diminuição do tempo de leitura em relação ao gasto com o uso de duas lâminas?.

Sabidamente a técnica de coleta é elemento crítico para o desempenho ideal do exame de Papanicolaou e a adequabilidade do esfregaço é avaliada pela presença de células escamosas e/ou colunares no raspado. Em nosso país, o Programa de Controle do CC indica que a coleta seja obtida da zona de transformação (ectocérvix) utilizando espátula de Eyre, que anatomicamente se adapta à região, e escova endocervical que possa "varrer" as criptas localizadas no canal endocervical. O valor desta metodologia com utilização para a coleta da escova endocervical e espátula foi comprovada e demonstrou-se que, na presença de esfregaço inflamatório, decai razoavelmente a qualidade da análise ${ }^{16}$.

Em relação à seqüência de coleta, vários estudos advogam que primeiramente se colete material do canal e posteriormente da ectocérvix ${ }^{16,17}$. Caso não se obedeça a esta seqüência, o eventual sangramento após a raspagem do canal poderia limitar a leitura da lâmina, embora em outros estudos a seqüência de coleta não tenha influenciado os resultados ${ }^{16,18}$. 
Outro ponto importante diz respeito ao profissional que irá empreender a coleta. Alguns locais têm treinado profissionais não ginecologistas para este ato. Neste particular, Fiscella e Franks ${ }^{19}$, avaliando 34.916 exames de Papanicolaou coletados por 130 médicos de família (MF) e 88 ginecologistas e obstetras (GO), comparados pela regressão logística, não encontraram diferenças no índice de esfregaços satisfatórios quando comparados os dois grupos. Entretanto, quando o material foi coletado por MF, a ausência do componente endocervical ocorreu 1,5 vezes mais que no grupo coletado por GO. Concluem pela necessidade de treinamento adequado, quando se empregar MF para a coleta do Papanicolaou, sobretudo na obtenção adequada do material endocervical.

Ainda um ponto sem definição em nosso meio é a idade de início da coleta e o intervalo entre elas. Quanto ao primeiro, é considerado como adequado iniciar a coleta após três anos do início da atividade sexual ${ }^{20}$. Quanto ao intervalo, é indicada a coleta a cada três anos, para aquelas que apresentaram dois laudos anteriores negativos ${ }^{7,21}$. Em relação aos programas de prevenção do CC, embora desde 1984, através do Programa do Ministério de Saúde chamado Viva Mulher ele tenha sido implementado no Brasil, analisando-se os dados até 2002 não se observam resultados satisfatórios. Prova disto é que dados do Instituto Mundial de Pesquisas e Análises do Câncer (IARC), avaliando dois programas de prevenção do câncer do colo uterino, do Brasil e do Reino Unido, demonstraram que, para nosso país, havia uma ascensão do número de casos, enquanto no Reino Unido foi observada a estabilização após implantado o programa. Referem a ausência de impacto da triagem nas jovens e participação limitada das mulheres adultas como sendo os motivos principais responsáveis por esse índice de falhas ${ }^{22}$.

Com finalidade de resolução destes problemas, o Ministério da Saúde, através do Inca, vem implementando campanhas que têm resolvido em parte estes problemas. O Programa de Controle do Câncer do Colo Uterino foi realmente implantado no país no ano 2000 e a segunda grande campanha, ocorrida em 2002, obteve os melhores resultados até então. Além da melhora dos resultados, esta campanha influiu decisivamente nos seguintes pontos:

1 Padronizou procedimentos de coleta e de conduta;

2 Ampliou o acesso não apenas ao rastreamento, mas, principalmente, ao tratamento pela cirurgia de alta freqüência;

3 Introduziu a metodologia "ver e tratar" na tentativa de resolver os casos de falta de retorno das pacientes com laudos alterados;

4 Implantou um programa de controle informatizado em toda a rede (SISCOLO);

5 Introduziu o conceito de seguimento na rede.

Houve uma tentativa de aumentar a cobertura do Papanicolaou, que entre 2000 e 2003 não passava dos $30 \%$ na média brasileira. Principalmente nos locais onde havia os menores índices de cobertura, as ações foram focadas, sendo que, nestes centros, os melhores resultados foram observados. Em relação a esta média de cobertura bastante baixa no país, Pinho et al. ${ }^{23}$, em estudo entre 1.172 mulheres na cidade de São Paulo no ano de 2000, demonstraram que as pacientes com maiores níveis de escolaridade e melhor nível socioeconômico eram aquelas que mais aderiam ao rastreamento. Entre as que não procuravam os serviços, observaram que a maioria referia que se sentiam saudáveis e sem problemas ginecológicos, não vendo esta necessidade (45\%), além de um contingente significativo que referia vergonha e medo do exame $(32 \%)$ e outras que não conseguiam vaga para a consulta $(11 \%)$.

Outro problema ocorrido foi que ainda o fornecimento de adequado tratamento aos casos detectados apresentava restrições, com dados ainda inconsistentes. Igualmente, em relação à qualidade dos laudos dos laboratórios de citopatologia, foram implementadas medidas de controle de qualidade, e inclusive alguns estudos foram publicados utilizando estes dados ${ }^{8,13}$.

Assim sendo, até que recentes metodologias se tornem usuais, acessíveis e padronizadas em nosso meio, deveremos tentar intervenções que possam fazer com que as pacientes compareçam para coleta de seu exame "preventivo" aderindo aos programas de prevenção do CC, bem como tentar obter resultados de sensibilidade e especificidade cada vez melhores, com a clássica metodologia de Papanicolaou. 


\section{Referências}

1. Parkin DM, Bray F, Ferlay J, Pisani P. Global cancer statistics, 2002. CA Cancer J Clin. 2005;55(2):74-108.

2. Ministério da Saúde. Secretaria de Atenção à Saúde. Instituto Nacional de Câncer. Coordenação de Prevenção e Vigilância. Estimativa 2006: incidência de câncer no Brasil. Rio de Janeiro: Inca; 2005.

3. Gustafsson L, Ponten J, Zack M, Adami HO. International incidence rates of invasive cervical cancer after introduction of cytological screening. Cancer Causes Control. 1997;8(5):755-63.

4. Papanicolaou GN, Traut HF. The diagnostic value of vaginal smears in carcinoma of the uterus. Am J Obstet Gynecol. 1941;42(2):193-205.

5. Papanicolaou GN. A new procedure for staining vaginal smears. Science. 1942;95(2469):438-9.

6. Anttila A, Nieminen P. Cervical cancer screening programme in Finland. Eur J Cancer. 2000;36(17):2209-14.

7. De Carvalho NS, Piazza M, Collaço LM, Chuery ACS, Utida GM, et al. Citologia oncótica: qual a metodologia ideal de coleta? Femina. 2002;30(1):9-12

8. Sebastião AP, Noronha L, Pinheiro DL, Collaço LM, de Carvalho NS, Bleggi-Torres LF. Influence of specimen adequacy on the diagnosis of ASCUS. Diagn Cytopathol. 2004;31(3):155-8.

9. Frable WJ. "Litigation cells" in the Papanicolaou smear: extramural review of "experts". Arch Pathol Lab Med. 1997;121(3):292-5.

10. The 1998 Bethesda System for reporting cervical/vaginal cytologic diagnoses: developed and approved at the National Cancer Institute Workshop in Bethesda, Maryland, December 12-13, 1988. Hum Pathol. 1990;21 (7):704-8.

11. Solomon D, Davey D, Kurman R, Moriarty A, O'Connor D, Prey M, et al. The 2001 Bethesda System: terminology for reporting results of cervical cytology. JAMA. 2002;287(16):2114-9.

12. Brasil. Ministério da Saúde. Secretaria de Atenção à Saúde. Instituto Nacional de Câncer. Coordenação de Prevenção e Vigilância. Nomenclatura Brasileira para Laudos Citopatológicos Cervicais e Condutas Clínicas Preconizadas. Brasília (DF): INCA; 2006. Rev Bras Ginecol Obstet. 200 ; 28(8): 486-504.

13. Sebastião APM, Noronha L, Scheffel DLH, Garcia M, de Carvalho NS, Collaço LM, et al. Estudo das atipias indeterminadas em relação à prevalência e ao percentual de discordância nos casos do Programa de Prevenção do Câncer Uterino do Paraná. J Bras Patol Med Lab. 2004;40(6):431-8.

14. Manrique EJC, Tavares SBN, Souza NLA, Albuquerque ZBP, Zeferino LC, Amaral RG. A revisão rápida de 100\% é eficiente na detecção de resultados falso-negativos dos exames citopatológicos cervicais e varia com a adequabilidade da amostra: uma experiência no Brasil. Rev Bras Ginecol Obstet. No prelo 2007.

15. Longatto Filho A, Almeida DCB, Adura PJD, Marzola VO, Cavaliere M. Influência da qualidade do esfregaço cérvico-vaginal na detecção de lesões intra-epiteliais cervicais. Folha Méd. 2002;121(2):79-83.

16. Marchand L, Mundt M, Klein G, Agarwal SC. Optimal collection technique and devices for a quality pap smear. WM. 2005;104(6):51-5.

17. Rahnama P, Faghihzadeh S, Ziaei S. Effect of the sampling sequence on the quality of Papanicolaou smear. Int J Gynecol Cancer. $2005 ; 15(1): 66-9$.

18. Noel ML, Kazal LA Jr, Glenday MC. Papanicolaou smear adequacy: the effect of the sampling sequence. J Am Board Fam Pract. 1993;6(2): 103-7.

19. Fiscella K, Franks P. The adequacy of Papanicolaou smears as performed by family physicians and obstetrician-gynecologists. J Fam Pract. $1999 ; 48(4): 294-8$

20. Noller KL. Cervical cytology screening and evaluation. Obstet Gynecol. 2005;106(2):391-7.

21. Franco R, Amaral RG, Montemor EBL, Montis DM, Morais SS, Zeferino LC. Fatores associados a resultados falso-negativos de exames citopatológicos do colo uterino. Rev Bras Ginecol Obstet. 2006;28(8):479-85.

22. Ferlay J, Bray F, Pisani P, Parkin DM. GLOBOCAN 2002: cancer incidence, mortality and prevalence worldwide. Version 2.0. Lyon: IARC Press; 2004. (IARC Cancer Base, 5).

23. Pinho AA, França Junior I, Schraiber LB, D’Oliveira AFPL. Cobertura e motivos para a realização ou não do teste de Papanicolaou no Município de São Paulo. Cad Saúde Pública. 2003;19 Supl 2:303-13. 